\title{
ELETROANÁLISE DE DERIVADOS ACETALDEÍDO COM HIDRAZINA E DETERMINAÇÃO EM AMOSTRAS DE ÁLCOOL COMBUSTÍVEL POR VOLTAMETRIA DE ONDA QUADRADA
}

\author{
Vanessa S. Rodgher, Nelson R. Stradiotto e Maria Valnice B. Zanoni* \\ Departamento de Química Analítica, Instituto de Química, Universidade Estadual Paulista, CP 355, \\ 14801-970 Araraquara - SP, Brasil \\ Aquiles A. Barros \\ REQUIMTE - Departamento de Química, Faculdade de Ciências do Porto, R. do Campo Alegre, 687, 4169-007 Porto - Portugal \\ Recebido em 14/3/05; aceito em 12/9/05; publicado na web em 14/3/06
}

\begin{abstract}
ELECTROANALYSIS OF ACETALDEHYDE DERIVATIZED WITH HYDRAZINE AND DETERMINATION IN FUEL ETHANOL BY SQUARE WAVE VOLTAMMETRY. A square wave voltammetric method is described for the determination of acetaldehyde using the derivatization reaction with hydrazine sulphate, based on the reduction of hydrazone generated as a product that exhibits a single well-defined peak at $-1.19 \mathrm{~V}$ in acetate buffer at $\mathrm{pH}$. Calibration graphs were obtained from $1.0 \times 10^{-6} \mathrm{~mol} \mathrm{~L}^{-1}$ to $10 \times 10^{-6} \mathrm{~mol} \mathrm{~L}^{-1}$ of acetaldehyde, using a reaction time of $8 \mathrm{~min}$ and a hidrazine concentration of $0.02 \mathrm{~mol} \mathrm{~L}^{-1}$. The detection limit was $2.38 \mathrm{x} 10^{-7}$ mol $\mathrm{L}^{-}$

${ }^{1}$. The method was applied satisfactorily to the determination of total aldehyde in fuel ethanol samples without any pre-treatment.
\end{abstract}

Keywords: acetaldehyde derivatization; reduction of acetaldehyde; fuel ethanol analysis.

\section{INTRODUÇÃOO}

O uso de etanol como combustível automobilístico ou aditivo de gasolina no Brasil tem aumentado dramaticamente desde 1975, como conseqüência do lançamento do Programa Nacional de Álcool que tinha como foco principal a criação estratégica de fontes alternativas de energia às crises de petróleo. A produção anual de etanol combustível no país gira em torno de 14 bilhões $\mathrm{m}^{3} / \mathrm{ano}$, o que o classifica como um dos maiores produtores do mundo ${ }^{1,2}$.

Devido à sua importância na economia e no desenvolvimento tecnológico nacional, o controle de qualidade do álcool produzido e disponível comercialmente requer métodos analíticos cada vez mais sensíveis e seletivos para análise de seus contaminantes inorgânicos e orgânicos ${ }^{3,4}$. Embora estes contaminantes desempenhem um papel quantitativamente secundário no álcool produzido, o conhecimento e controle dessas impurezas assumem papel principal quando empregado em motores desenvolvidos com alta tecnologia ou utilizado em processos químicos sofisticados.

Aldeídos de baixo peso molecular, particularmente acetaldeído, constituem um contaminante orgânico importante em etanol combustível, cuja análise requer métodos com sensibilidade compatível com a complexidade da amostra, que pode apresentar acentuada modificação de concentração, presentes desde grau majoritário, até teores mais baixos após envelhecimento ou armazenamento do produto. Em adição, são poluentes importantes da atmosfera urba$\mathrm{na}^{5}$, de águas ${ }^{6}$ e em clínica médica ${ }^{7}$.

Os métodos analíticos disponíveis na literatura para quantificação de acetaldeído podem ser classificados dentro de duas categorais principais: determinação direta por técnicas espectroscópicas ou combinando reações de derivatização e métodos espectrofotométricos e cromatográficos ${ }^{8-23}$. Dentre estes, o método mais comum de derivatização envolve o uso do reagente 2,4-dinitrofenilidrazina (DNPH), que possue como característica básica a reação com grupos carbonilas e formação da hidrazona correspondente.

\footnotetext{
*e-mail: boldrinv@iq.unesp.br
}

A aplicação de técnicas eletroquímicas para quantificação de acetaldeído tem sido limitada, devido ao alto potencial requerido para sua redução direta em solventes apróticos $\left(\mathrm{E}_{1 / 2}\right.$ entre -2,2 a $-2,8 \mathrm{~V}$ vs SCE $)^{24}$. No entanto, considerando que a maioria dos compostos contendo o grupo carbonila pode reagir com uma ampla variedade de aminas, resultando em compostos com o grupo $>\mathrm{C}=\mathrm{N}$-, facilmente redutível, seria interessante investigar o comportamento eletroquímico de derivados de acetaldeído usando hidrazinas como agente derivatizante. $\mathrm{O}$ uso de hidrazina como agente derivatizante de aldeídos totais tem sido descrito na literatura como um método indireto para quantificação de dióxido de enxofre em amostras de cerveja ${ }^{25,26}$. De acordo com os autores, o produto da reação entre hidrazina e acetaldeído/SO $\mathrm{S}_{2}$ pode ser reduzido voltametricamente sobre eletrodo de mercúrio e determinado através de polarografia de pulso diferencial e onda quadrada. Entretanto, a redução voltamétrica de acetaldeído ou aldeídos totais derivados com hidrazina em amostras de etanol combustível não tem sido descrita na literatura.

Deste modo, o presente trabalho relata o estudo eletroquímico do produto da derivatização de acetaldeído com sulfato de hidrazina em meio aquoso sobre eletrodo de mercúrio utilizando-se a técnica de voltametria de onda quadrada, visando investigar a potencialidade do método eletroanalítico para sua determinação. Em adição, o método é empregado para quantificação de aldeídos alifáticos totais em amostra de etanol combustível.

\section{PARTE EXPERIMENTAL}

Todas as medidas voltamétricas foram realizadas em um Potenciostato/Galvanostato EG\&G Instruments (Princeton Apllied Research), modelo 283, interfaciado, conectado a um sistema de três eletrodos da EG\&G PARC, modelo 303 A, contendo um eletrodo de gota pendente de mercúrio (HMDE) como eletrodo de trabalho, um eletrodo de referência de $\mathrm{Ag} / \mathrm{AgCl}\left(\mathrm{KCl} \mathrm{3,0} \mathrm{mol} \mathrm{L}{ }^{-1}\right)$ e um fio de platina como eletrodo auxiliar. As medidas de $\mathrm{pH}$ foram realizadas em pHmetro da Micronal modelo B222 usando eletrodo de vidro combinado. 
A reação entre acetaldeído da Merck (Darmstadt, Germany) e sulfato de hidrazina da Aldrich Chemical Co. (Milwaukee, USA) foi monitorada através do seguinte procedimento; uma solução aquosa de sulfato de hidrazina foi preparada e adicionada em uma cela voltamétrica termostatizada à temperatura de $10{ }^{\circ} \mathrm{C}$, contendo 5 $\mathrm{mL}$ de solução tampão acetato $0,1 \mathrm{~mol} \mathrm{~L}^{-1} \mathrm{pH} 5$, para concentração final de $0,02 \mathrm{~mol} \mathrm{~L}^{-1}$. Após borbulhamento de gás nitrogênio durante $10 \mathrm{~min}$, adicionaram-se alíquotas de solução aquosa recém preparada de acetaldeído, e os voltamogramas de onda quadrada foram registrados após 8 min de reação. Água desmineralizada proveniente de sistema Milli-Q (Millipore, USA) foi utilizada no preparo de todas as soluções.

\section{RESULTADOS E DISCUSSÃO}

Acetaldeído não é reduzido sobre eletrodo de mercúrio em solução de tampão acetato $\mathrm{pH}$ 5, como mostram os voltamogramas de onda quadrada da Figura 1, curva a. Do mesmo modo, voltamogramas de hidrazina sob as mesmas condições experimentais não apresentam nenhuma onda de redução. No entanto, o voltamograma de onda quadrada, obtido para solução $0,02 \mathrm{~mol} \mathrm{~L}^{-1}$ de sulfato de hidrazina na presença de $1 \times 10^{-4} \mathrm{~mol} \mathrm{~L}^{-1}$ acetaldeído sobre eletrodo de mercúrio, em tampão acetato $\mathrm{pH} 5$, caracteriza-se por um pico catódico bem definido em potencial de $-1,19 \mathrm{~V}$, como mostra a curva $\mathrm{b}$ da Figura 1.

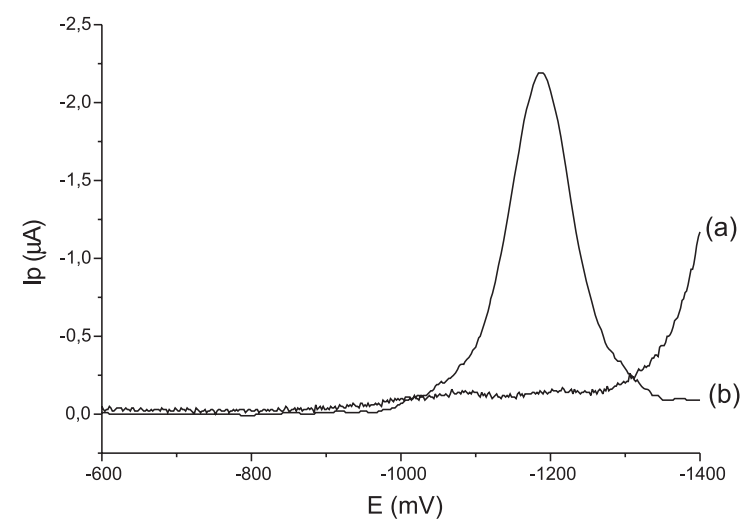

Figura 1. Voltamogramas de onda quadrada da redução de 0,02 $\mathrm{mol} \mathrm{L}^{-1}$ de hidrazina em tampão acetato $\mathrm{pH} 5$ sobre eletrodo de gota pendente de mercúrio na ausência (a) e presença (b) de $1 \times 10^{-4} \mathrm{~mol} \mathrm{L^{-1 }}$ de acetaldeído. Freqüência $=25 \mathrm{~Hz}$. Amplitude pulso $=50 \mathrm{mV}$ e degrau de impulso $=2 \mathrm{mV}$

É bem conhecido da literatura ${ }^{24-29}$ que compostos contendo grupo amino $\left(-\mathrm{NH}_{2}\right)$ condensam facilmente com compostos carbonílicos (acetaldeído) para dar produtos de adição com ligação $-\mathrm{C}=\mathrm{N}$ resultante da eliminação de água, de acordo com a Equação 1

$\mathrm{RCHO}+\mathrm{H}_{2} \mathrm{~N}-\mathrm{NH}_{2} \rightarrow \mathrm{RCH}=\mathrm{N}-\mathrm{NH}_{2}+\mathrm{H}_{2} \mathrm{O}$

No entanto, estudos prévios sobre eletroquímica de hidrazonas e outros derivados ${ }^{25-29}$ indicam que o mesmo pode ser complicado pela ocorrência de diferentes formas tautoméricas em função da variação de $\mathrm{pH}$, como mostra a Equação 2

$\underset{\text { (I) }}{\mathrm{RCH}-\mathrm{N}=\mathrm{NH}_{2}} \underset{\text { (II) }}{\mathrm{R}-\mathrm{CH}=\mathrm{N}-\mathrm{NH}_{2}} \underset{\text { (III) }}{\mathrm{R}=\mathrm{CHNHNH}_{2}}$

Em meio ácido, como utilizado no presente trabalho, a forma (II) é predominante, não sendo encontradas as formas (I) e (III), que podem complicar o mecanismo de derivatização pela ocorrên- cia preferencial em condições muito ácidas, ou alcalinas, respectivamente $^{25-29}$. Deste modo, os estudos eletroquímicos visando monitoramento de acetaldeído na presença de hidrazina foram realizados em meio de $\mathrm{pH} \leq 6,0$. No intervalo de $\mathrm{pH}$ entre $4,0<\mathrm{pH}<$ 6,0 , os voltamogramas de onda quadrada apresentaram corrente aproximadamente constante, porém exibem uma acentuada diminuição da intensidade do pico em $\mathrm{pH}<3,5$. Deste modo, adotou-se pH 5,0 como melhor condição experimental para formação e monitoramento do sinal voltamétrico proveniente da reação entre acetaldeído e sulfato de hidrazina.

Assim, nestas condições experimentais é possível sugerir que, embora acetaldeído e hidrazina não sejam reduzidos no intervalo útil de potencial utilizado em tampão acetato como eletrólito de suporte, a redução do derivado acetaldeído-hidrazona ocorre segundo transferência de dois elétrons e dois prótons ${ }^{25,30}$, de acordo com a Equação 3

$\mathrm{RCH}=\mathrm{N}-\mathrm{NH}_{2}+2 \mathrm{H}^{+}+2 \mathrm{e}^{-} \rightarrow \mathrm{RCH}_{2}-\mathrm{NH}-\mathrm{NH}_{2}$

A influência de alguns parâmetros inerentes da técnica de voltametria de onda quadrada no sinal voltamétrico foi investigada a seguir, com o intuito de otimizar as condições para monitoramento da redução do composto acetaldeído-hidrazona. Dentro deste contexto, registraram-se voltamogramas de onda quadrada para solução de hidrazina $0,02 \mathrm{~mol} \mathrm{~L}^{-1}$ na presença de $1 \times 10^{-4} \mathrm{~mol} \mathrm{~L}^{-1}$ de acetaldeído após 10 min de reação sob condições de freqüência $(f)$ entre 10 a $100 \mathrm{~Hz}$, amplitude de pulso $(\Delta \mathrm{E})$ entre 10 a $50 \mathrm{mV}$ e degrau de impulso $\left(\Delta \mathrm{E}_{\mathrm{s}}\right)$ entre 1 a $5 \mathrm{mV}$. As melhores condições experimentais para análise do acetadeído derivatizado com hidrazina foram freqüência de $25 \mathrm{~Hz}$, amplitude de pulso de $50 \mathrm{mV}$ e degrau de impulso de $2 \mathrm{mV}$.

Considerando que o sinal analítico pode ser alterado em função de parâmetros inerentes da reação, investigou-se a seguir o efeito do tempo de reação, estabilidade do produto formado e efeito da concentração dos reagentes na reação de derivatização, com o intuito de definir as melhores condições reacionais para formação do derivado acetaldeído: hidrazina.

A influência do tempo de reação entre sulfato de hidrazina e acetaldeído para formação da respectiva hidrazona em meio aquoso foi investigada através do monitoramento de voltamogramas, registrados após reação entre $0,02 \mathrm{~mol} \mathrm{~L}^{-1}$ de hidrazina e $2 \times 10^{-4}$ mol L $\mathrm{L}^{-1}$ de acetaldeído, diretamente na cela voltamétrica. Os respectivos valores de corrente de pico obtidos entre tempos de reação entre 0 e 15 min foram colocados em gráfico e mostrados na Figura 2. Observa-se a ocorrência do pico em $-1,19 \mathrm{~V}$ mesmo após

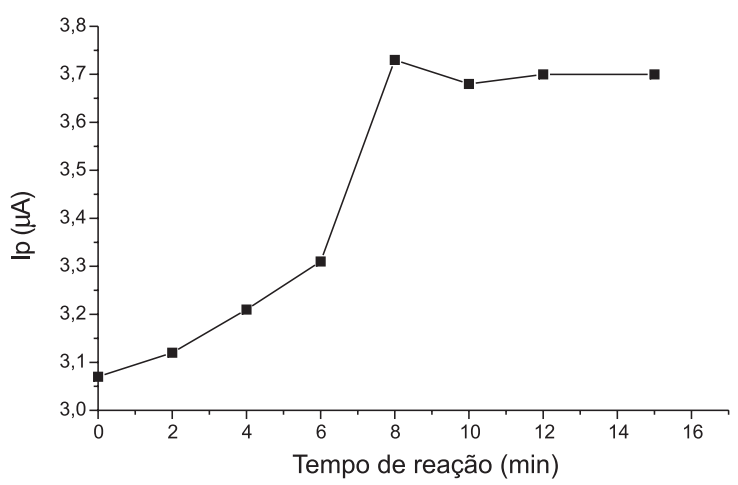

Figura 2. Efeito do tempo de reação entre $0,02 \mathrm{~mol} \mathrm{~L}^{-1}$ de hidrazina e $2 \times 10^{-4}$ mol $L^{-1}$ de acetaldeído em tampão acetato $\mathrm{pH} 5$, sobre a corrente de pico dos voltamogramas de onda quadrada registrados sobre eletrodo de gota pendente de mercúrio 
a imediata adição de acetaldeído, indicando que o composto é formado instantaneamente. Entretanto, a corrente de pico aumenta ligeiramente até $\mathrm{t}=8 \mathrm{~min}$ e permanece praticamente constante em tempos superiores, indicando o término da reação entre hidrazina e acetaldeído. Deste modo, estipulou-se um tempo de reação de 8 min como tempo ótimo de reação para as medidas posteriores.

$\mathrm{O}$ efeito da estabilidade do composto formado foi investigado através do registro de sucessivos voltamogramas de onda quadrada entre 0 e 60 min, após 8 min de reação entre hidrazina e acetaldeído. Os valores de corrente de pico permanecem constantes no intervalo de tempo entre 0 e 20 min após o término da reação, com um coeficiente de variação de $3 \%$ entre três medidas consecutivas. Em tempos superiores observa-se um decréscimo na corrente de pico culminando em uma queda de $21 \%$ após 40 min de reação. Estes resultados indicam que o produto formado se decompõe lentamente em solução, porém pode ser analisado com alta precisão no intervalo entre 0 e 20 min de reação. Nas medidas a seguir, adotou-se o procedimento de registrar os voltamogramas imediatamente após o termino da reação de 8 min entre hidrazina e acetaldeído.

O efeito da concentração de hidrazina sobre a curva voltamétrica correspondente à redução do produto da reação com acetaldeído foi investigado em tampão acetato $\mathrm{pH} 5$, fixando-se a concentração de acetaldeído em $1 \times 10^{-4} \mathrm{~mol} \mathrm{~L}^{-1}$ e variando-se a concentração de sulfato de hidrazina entre $1 \times 10^{-4}$ e $3 \times 10^{-2} \mathrm{~mol} \mathrm{~L}^{-1}$, com o intuito de otimizar a concentração de hidrazina para determinação indireta de acetaldeído. Os resultados são mostrados a seguir na Figura 3. A corrente de pico aumenta em função da concentração de hidrazina até uma concentração máxima de aproximadamente 2 x $10^{-2} \mathrm{~mol} \mathrm{~L}^{-1}$, concomitante a um acentuado deslocamento do potencial de pico para valores menos negativos. Estes resultados indicam que as melhores condições experimentais para derivatização de acetaldeído são aquelas obtidas na presença de excesso do derivatizante de pelo menos cem vezes em relação à concentração de acetaldeído, adotando-se a seguir valores maiores que $0,12 \mathrm{~mol}$ $\mathrm{L}^{-1}$ de hidrazina.

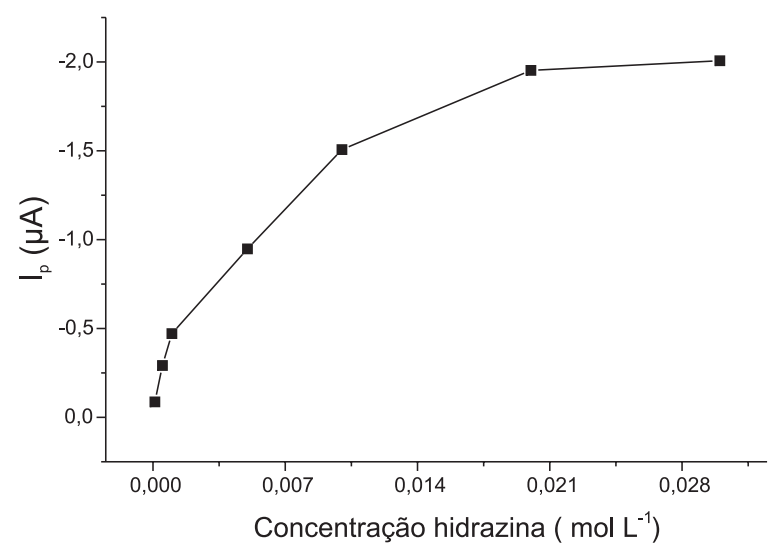

Figura 3. Relação entre corrente de pico e concentração de hidrazina obtida de voltamogramas de onda quadrada na presença de $1 \times 10^{-4} \mathrm{~mol} \mathrm{~L}^{-1}$ de acetaldeído em tampão acetato pH 5

Após a otimização das condições experimentais para monitoramento da redução do derivado acetaldeído/hidrazina por voltametria de onda quadrada, investigou-se o efeito da concentração de acetaldeído entre $1 \times 10^{-6}$ a $10 \times 10^{-6} \mathrm{~mol} \mathrm{~L}^{-1}$ na presença de 0,02 mol L-1 de hidrazina em tampão acetato $\mathrm{pH} 5$. Uma relação linear foi obtida em todo o intervalo investigado de $1,0 \times 10^{-6}$ a $1,0 \times 10^{-5} \mathrm{~mol}$ $\mathrm{L}^{-1}$, como mostra a Figura 4, cuja região linear pode ser representada pela seguinte equação: ip $(n A)=20,348+5,942 x$

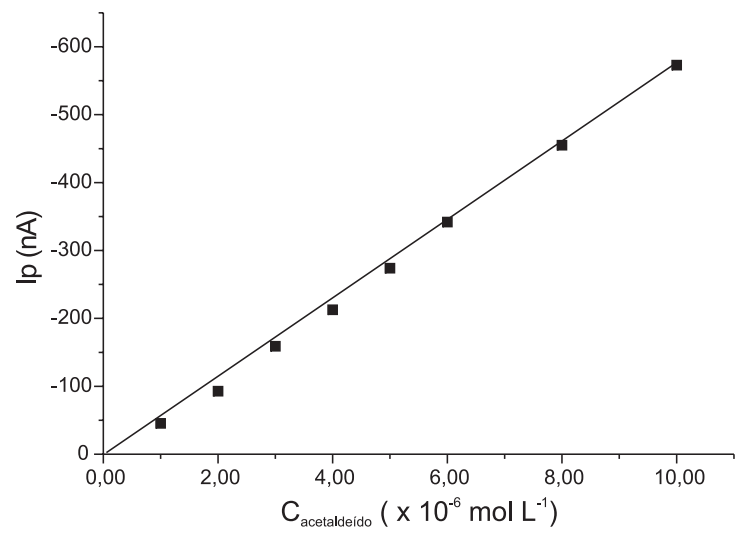

Figura 4. Curva analítica para determinação de acetaldeído via derivação com acetaldeído em tampão acetato pH 5, usando redução do produto sobre eletrodo de gota pendente de mercúrio

$10^{7} \mathrm{C}\left(\mathrm{mol} \mathrm{L}^{-1}\right), \mathrm{r}=0,9987, \mathrm{n}=8$. O limite de detecção calculado pela relação estatística usual $(3 \sigma / \theta)$ é de $2,4 \times 10^{-7} \mathrm{~mol} \mathrm{~L}^{-1}$. A repetibilidade das medidas voltamétricas foi testada registrandose curvas correspondentes a repetições de 5 soluções contendo $5 \mathrm{x}$ $10^{-5} \mathrm{~mol} \mathrm{~L}^{-1}$ de acetaldeído derivatizado com $0,02 \mathrm{~mol} \mathrm{~L}^{-1}$ de hidrazina em tampão acetato $\mathrm{pH} 5$, obtendo-se um coeficiente de variação de $3,1 \%$.

\section{Aplicação do método}

A aplicação do método foi testada na determinação de aldeídos totais, expresso como acetaldeído ${ }^{23}$ em cinco amostras de álcool combustíveis coletadas na região de Araraquara. Para tal, a redução voltamétrica do produto derivatizado foi registrada após transferência de $1 \mathrm{~mL}$ de álcool combustível diretamente para as células contendo $5 \mathrm{~mL}$ de solução tampão pH 5,0 e 0,02 mol L-1 de hidrazina (Figura 5). No voltamograma da Figura 5a, observa-se a presença de um pico de redução bem definido em potencial de $1,20 \mathrm{~V}$, cuja corrente aumenta em função da adição do padrão de acetaldeído (Figura 5 b). Os resultados correspondentes á concentração de aldeído total, expresso como acetaldeído em cada amostra de etanol combustível segundo o método proposto e a consequiente recuperação após adição do padrão à amostra são exibidos na Tabela 1. Em geral, as variações no conteúdo de acetaldeído nas amostras de etanol combustível encontradas foram valores entre $1,9 \times 10^{-3} \mathrm{~mol} \mathrm{~L}^{-1}$ a $7,7 \times 10^{-3} \mathrm{~mol} \mathrm{~L}^{-1}$. A repetibilidade do método foi testada repetindo-se 5 determinações para cada amostra, antes e após adição de solução padrão de acetaldeído e os resultados mostraram uma recuperação entre 95 a 101\%, com coeficiente de variação máximo de $3,2 \%$.

\section{CONCLUSÃO}

A aplicação do método eletroanalítico para análise direta de acetaldeído em meio aquoso sobre eletrodo de mercúrio é limitada pelo alto potencial requerido para sua redução, sendo visível apenas em condições de eletrólito contendo íons $\mathrm{Li}^{+29}$. No entanto, embora a maioria dos estudos envolvendo derivatização de acetaldeído baseie-se na reação com 2,4-dinitrofenilidrazina e no monitoramento do produto por métodos cromatográficos e espectrofotométricos, nossos resultados demonstram que a reação entre sulfato de hidrazina e acetaldeído em meio ácido de pH 5 pode ser uma excelente alternativa em relação às técnicas usuais.

$\mathrm{O}$ método baseia-se na redução da ligação $-\mathrm{C}=\mathrm{N}-$, presente no 
Tabela 1. Determinação de aldeído total em amostras de etanol combustível pelo método voltamétrico de onda quadrada após derivatização com hidrazina.

\begin{tabular}{|c|c|c|c|c|}
\hline \multirow[b]{2}{*}{ Amostra } & \multicolumn{4}{|c|}{ Aldeído total $/ \mathrm{mmol} \mathrm{L}^{-1}$ acetaldeído } \\
\hline & Método proposto & $\begin{array}{c}\text { Concentração adicionada } \\
\text { à amostra }\end{array}$ & $\begin{array}{c}\text { Concentração } \\
\text { encontrada }\end{array}$ & $\begin{array}{c}\text { Recuperação } \\
\%(\mathrm{CV})\end{array}$ \\
\hline $\mathrm{S}_{1}$ & 2,423 & 0,364 & 2,815 & $101 \pm 2$ \\
\hline $\mathrm{S}_{2}$ & 2,557 & 0,727 & 3,218 & $98 \pm 2$ \\
\hline $\mathrm{S}_{3}^{2}$ & 1,851 & 0,977 & 2,690 & $95 \pm 3$ \\
\hline $\mathrm{S}_{4}$ & 7,741 & 0,864 & 8,347 & $97 \pm 1$ \\
\hline $\mathrm{S}_{5}^{4}$ & 6,142 & 0,977 & 6,834 & $96 \pm 1.8$ \\
\hline
\end{tabular}

CV (Coeficiente de variação), $\mathrm{n}=3$.

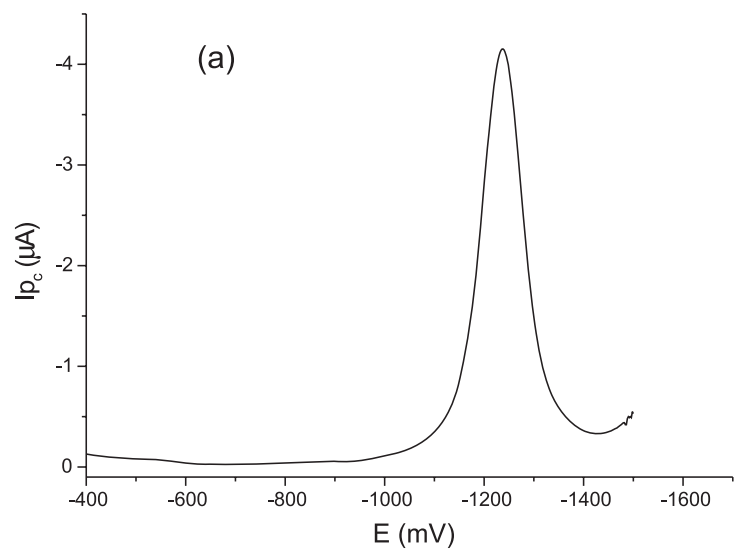

(b)

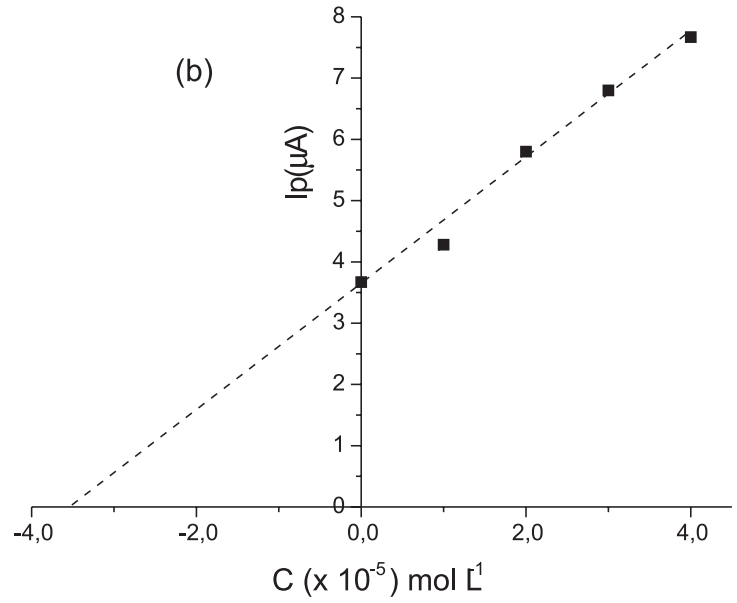

Figura 5. (a) Voltamograma de onda quadrada obtido para $1 \mathrm{~mL}$ de amostras de álcool combustível coletadas na região de Araraquara diluídas em $5 \mathrm{~mL}$ de tampão acetato pH 5 contendo sulfato de hidrazina 0,12 $\mathrm{mol} \mathrm{L}^{-1}$. (b) Curva da adição de padrão à amostra. Tempo de reação 8 min. $T=10^{\circ} \mathrm{C}$. Frequiência $=25 \mathrm{~Hz}$. Amplitude pulso $=50 \mathrm{mV}$ e degrau de impulso $=2 \mathrm{mV}$

derivado hidrazona formado após 8 min de reação diretamente na célula voltamétrica e monitoramento da onda bem-definida em potencial de $-1,19 \mathrm{~V}$ vs $\mathrm{Ag} / \mathrm{AgCl}$ por voltametria de onda quadrada. O método permite a determinação de aldeído total, expresso como acetaldeído, em amostras de álcool combustível sem qualquer pré-tratamento. A facilidade, rapidez e precisão do método proposto levam a concluir que o método eletroanalítico baseado na reação com sulfato de hidrazina pode ser uma excelente alternativa para estas amostras, em relação ás técnicas usuais que requerem etapas de pré-tratamento e extração.

\section{AGRADECIMENTOS}

À Agência Nacional do Petróleo (ANP), FINEP, CNPq, CAPES pelo auxílio financeiro e à FAPESP pela bolsa de IC concedida a V. S. Rodgher.

\section{REFERÊNCIAS}

1. http// www.unica.com.br/pages/alcool_combustível.asp, acessada em Maio 2005.

2. Snell, F. D.; Clifford L. H.; Encyclopedia of Industrial Chemical Analysis, Interscience: New York, 1974, vol. 4, p. 116 e 543.

3. Bruning, I. M. R. A.; Malm, E. B.; Bol. Tec. Petrobrás, Rio de Janeiro, 1982, 25, 217.

4. Andrade, M. V. A. S.; Pinheiro, H. L. C.; Pereira, P. A. P.; de Andrade, J. B.; Quim. Nova 2002, 25, 1117.

5. Kleinman, L. J.; J. Geophys. Res. 1991, 96, 20721.

6. Albert, R. E.; Sellakumar, A. R.; Laskin, S.; Kuschner, M.; Snyder, D. A.; J. Cancer Inst. 1982, 68, 597.

7. Tuma, D. J.; Sorrel, M. F.; Prog. Clin. Biol. Res. 1985, 183, 3.

8. Selim, S.; J. Chromatogr. 1977, 136, 271.

9. Kuwata, K.; Uebori, M.; Yamasaki, Y.; J. Chromatogr. Sci. 1979, 17, 264.

10. Whittle, P. J.; Rennie, J.; Analyst 1988, 113, 665.

11. Zurek, G.; Luftmann, H.; Karst, U.; Analyst 1999, 124, 1291

12. Altshuler, P.; Miller, D. L.; Slevo, S. F.; Anal. Chem. 1961, 33, 621.

13. Papa, L. P.; Environ. Sci. Technol. 1969, 3, 397.

14. Cardoso, A. A.; Pereira, E. A.; Anais Assoc. Bras. Quím. 1999, 48, 63.

15. AOAC; Official methods of Analysis of the Association of Official and Analytical Chemists, Washington, D.C., 1975, p. 1094.

16. Shiomi, K. J.; High Resolut. Chromatogr. 1991, 14, 136

17. Grosjean, D.; Fung, K.; Anal. Chem. 1982, 54, 1221.

18. Potter, W.; Karst, U.; Anal. Chem. 1996, 68, 3354.

19. Kiba, N.; Yagi, R.; Sun, L.; Tachibana, M.; Tani, K.; Koizumi, H.; Suzuki, T.; J. Chromatogr., A 2000, 886, 83.

20. Possanzini, M.; Di Palo, V.; Cecinato, A.; Atmos. Environ. 2003, 37, 1309.

21. Ho, S. S. H.; Yu, J. Z.; Environ. Sci. Technol. 2004, 38, 862.

22. Jacobs, W. A.; Kissinger, P. T.; J. Liquid Chromatogr. 1982, 5, 669.

23. Oliveira, F. S.; Leite, B. C. O.; Andrade, M. V. S.; Korn, M.; J. Braz. Chem. Soc. 2005, 16, 87.

24. Baizer, M. M.; Lund, H.; Organic Electrochemistry, $2^{\text {nd }}$ ed., Marcel Dekker Inc.: New York, 1983, cap. 9.

25. Almeida, P. J.; Rodrigues, J. A.; Guido, L.F.; Santos, J. R.; Barros, A.A.; Fogg, A.G.; Electroanalyis 2003, 15, 587.

26. Guido, L. F.; Fortunato, N. A.; Rodrigues, J. A.; Barros, A. A.; J. Agric. Food Chem. 2003, 51 , 3911.

27. Afghan, B. K.; Kulkarni, A. V.; Ryan, J. F.; Anal. Chem. 1975, 47, 488.

28. Zuman, P.; Organic Polarographic Analysis, The Macmillan Company: New York, 1964, p. 19.

29. Bard, A. J.; Lund, H.; Encyclopedia of Electrochemistry of the Elements, New York, Vol. XII, p. 156. 